Original article

https://www.journal-imab-bg.org

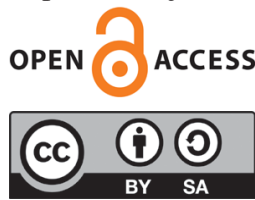

\section{MUSCULOSKELETAL DISORDERS AND ASSO- CIATED WORKPLACE RISK FACTORS IN HIGHER EDUCATION EMPLOYEES}

\author{
Gergana Sandeva ${ }^{1}$, Violeta Tsvetkova ${ }^{2}$, Gospodinka Prakova ${ }^{2}$ \\ 1) Department of Hygiene, Epidemiology, Infectious Diseases, Microbiology and \\ Parasitology, Medical Faculty, Trakia University, Stara Zagora, Bulgaria. \\ 2) First Department of Internal Diseases and General Medicine, Medical Fac- \\ ulty, Trakia University, Stara Zagora, Bulgaria.
}

\section{ABSTRACT:}

Introduction: Work-related musculoskeletal disorders (MSDs) are caused by a variety of environmental and organizational workplace factors, which makes them some of the most commonly reported work-related health problems in Europe and the world.

Our purpose was to determine the prevalence of musculoskeletal complaints among employees in higher education, as well as the most significant risk factors for their occurrence.

Material/Methods: The survey was conducted among 542 employees of Trakia University, Bulgaria, using questionnaires on symptoms and exposure to the most common occupational risk factors for MSDs. The subjects were grouped and compared by gender, age, years of service and employment position.

Results: $74 \%$ of participants reported one or more musculoskeletal complaints, with the most common locations being the lower and upper back, neck, and shoulders. Women had a significantly higher average number of complaints (2.41) than men (1.64), p =0.000058. A higher percentage of hand/arm MSDs was reported by auxiliary workers, and lower back complaints were more frequently reported by administrative staff, compared to other groups. A positive correlation was found between the number of MSDs and the years of service $(r=0.11, p=0.019)$, but not between MSDs and age. The major reported workplace risk factors for MSDs were working with display screen equipment (55.9\% of respondents), frequent, repetitive hand movements $(37.46 \%)$, and non-ergonomic workstations/arrangements $(27.67 \%)$.

Conclusions: Prevention of MSDs of occupational origin requires a comprehensive approach involving the identification, assessment and control of a number of ergonomic and organizational factors. Similar studies in other occupational groups would help to better understand and prevent these chronic, painful and often disabling diseases.

Keywords: musculoskeletal disorders, risk factors, higher education

\section{INTRODUCTION}

Work-related musculoskeletal disorders (WRMSDs) have become some of the most common health issues of the employed population in recent years. In the European Union, information from national sources shows that a very large percentage of workers report being affected by musculoskeletal disorders (MSDs). In some Member States (Germany, Spain, Italy, Austria), MSDs are the top work-related health problem [1]. Back pain is the most commonly identified health issue, followed by pain in the neck, shoulders and upper limbs. Generally, MSD prevalence rates are higher for female workers than for male workers, and for older workers than for their younger counterparts.

MSDs have a substantial impact not only on workers' well-being in daily life, but also in economic terms, as they lead to a loss of productivity at work and to increased social expenses (for instance, sick leave expenses), in terms of both direct costs (contributions and compensations paid by companies, costs paid for health care and medication, etc.) and, in some cases, indirect costs (disruptions in working teams, decreased productivity, production delays, production losses caused by reduced ability to work and by sick leave) [1]. In France, for example, direct annual costs due to WRMSDs exceed EUR 1 billion, with more than half related to paid sick leave. Indirect costs could be up to ten times higher. In Germany, MSDs incur higher costs than any other disease diagnosis group: around EUR 17.2 billion in production losses (production loss costs based on labour costs) and a EUR 30.4 billion loss of gross value added (based on loss of labour productivity). Most recently, EU-OSHA recognized the importance of work-related MSDs in terms of health and labour costs and dedicated their 2020-2022 Safe Workplaces Campaign to MSDs with the slogan, "Lighten the Load".

There are a number of physical, organizational, psychosocial and sociodemographic work-related risk factors that contribute to the onset of MSDs or to the aggravation of existing ones [2]. Studies have established a positive link between physically demanding working conditions and their negative influence on the musculoskeletal (MS) system. The most frequently reported occupational risks are postural and joint constraints, standing or working upright, 
walking during work, manual load handling, repetitive tasks, very rapid hand movements, visual display unit (VDU) work, a static working posture, and heavy physical work [3]. Additionally, several organizational and psychosocial factors that lead to acute or chronic stress may have an impact on the musculoskeletal health of workers, including significant time pressure/work overload, harassment/ bullying in the workplace, conflict with the boss or peers, work rhythm constraints, and insufficient work breaks, among others [2].

As a rule, higher prevalence of MSDs is reported in specific sectors such as construction, agriculture/fisheries, industry, transport, and health care, therefore the majority of studies focus on those particular sectors. Nevertheless, WRMSDs are widely present in all occupational spheres; therefore, current epidemiological studies should look into other economic sectors as well. Education is a chronically underfunded sector in many countries, and its working conditions and work environment hazards could potentially have a detrimental effect on workers' health in terms of increased risk of MSDs. In recent years, this has led more scientists to take notice of the ergonomic and organizational hazards associated with MSDs in all levels of education (elementary, general, higher), as well as the prevalence of these disorders among both teachers and students [4-7].

Successful prevention of WRMSDs in the education sector requires not only tracking the prevalence of MS complaints among various professional groups but also an extensive study of the occupational hazards leading to these disorders at the specific educational institution. Therefore, the purpose of our study was to determine the prevalence of musculoskeletal complaints among employees in a university setting, as well as the most significant risk factors for their occurrence.

\section{MATERIALS AND METHODS}

The study was conducted among employees from all administrative departments and faculties of Trakia University, Bulgaria: Faculty of Medicine, Faculty of Agriculture, Faculty of Veterinary Medicine, Department for Information and In-Service Teachers Training, Medical College, University Hospital, Faculty of Education, Faculty of Economics, Haskovo Branch, Faculty of Engineering and Technology - Yambol, and Rector's Office. Two questionnaires were used in the study: the standardized Nordic Musculoskeletal Disorders Questionnaire and a specially designed Occupational Risk Factors Questionnaire, listing 14 occupational hazards associated with MSDs most frequently reported in the literature, and their exposure time [8]. The musculoskeletal questionnaire was slightly modified as well, to include an additional question on the type of complaints about each body part (ache/_pain at rest or during movement, discomfort, stiffness, muscle weakness, etc.). The surveys used were approved by the Ethics Committee of the Medical Faculty, Trakia University. The studied subjects were later divided into groups based on their gender, age, years of work experience at the university, and employment position (table 1.). The employment classification was as follows: tutors (teachers, professors and assist- ant professors), administrative employees, and auxiliary workers (including cleaners, security workers, lab technicians and others, mainly occupied in physical work).

Table 1. Distribution by sex, age, years of service at the university, and employment position of the studied cohort.

\begin{tabular}{|c|c|c|}
\hline Determinant & Number $(\mathbf{N})$ & Percent (\%) \\
\hline \multicolumn{3}{|l|}{ Sex } \\
\hline Female & 370 & 68.39 \\
\hline Male & 166 & 30.68 \\
\hline Didn't specify & 5 & 0.92 \\
\hline \multicolumn{3}{|l|}{ Age } \\
\hline $25-34$ & 56 & 10,35 \\
\hline $35-44$ & 118 & 21.81 \\
\hline $45-54$ & 139 & 25.69 \\
\hline $55-64$ & 195 & 36.04 \\
\hline$>65$ & 21 & 3,88 \\
\hline Didn't specify & 12 & 2,22 \\
\hline \multicolumn{3}{|c|}{ Years of experience } \\
\hline $0-9$ & 176 & 32.53 \\
\hline $10-19$ & 90 & 16.64 \\
\hline $20-29$ & 83 & 15.34 \\
\hline $30-39$ & 98 & 18,11 \\
\hline$>40$ & 4 & 0.74 \\
\hline Didn't specify & 90 & 16.64 \\
\hline \multicolumn{3}{|c|}{ Employment position } \\
\hline Tutor & 296 & 54.71 \\
\hline Administration & 98 & 18,11 \\
\hline Auxiliary & 112 & 20,7 \\
\hline Didn't specify & 35 & 6,47 \\
\hline
\end{tabular}

The collected data were statistically processed using the StatSoft Statistica v.12 software. The total number and percentage distribution of the studied parameters were calculated for each subgroup. Student's t-test and correlation analyses were also performed. A significance level of $5 \%$, i.e. $\mathrm{p}<0.05$, was accepted for all statistical analyses.

\section{RESULTS}

Out of the 904 employees at the university, 542 individuals returned correctly filled out forms $(59.95 \%$ response rate). The mean age of respondents was $49.98 \pm 10.4$ years, and their average work experience at the university was $16.68 \pm 12$ years. Almost $74 \%$ of responders experienced some kind of musculoskeletal issue in various body parts during the previous 12 months (table 2.), while $29.02 \%$ experienced symptoms in the previous 7 days. The mean number of reported complaints per individual was 2.29, with a significantly higher number of MS locations in female employees compared to the male, $p=0.000058$. In the subgroups divided by age, work experience and employment position, no significant differences were observed in the number of body parts affected by MSDs. 
Table 2. Musculoskeletal complaints among the studied employees during the last 12 months distributed by gender and employment position (number of locations and overall percentage).

\begin{tabular}{|l|l|l|l|l|l|l|l|l|l|l|l|}
\hline & None & One & Two & Three & Four & Five & Six & Seven & Eight & More than 8 & Mean \\
\hline Total & 141 & 115 & 87 & 65 & 60 & 33 & 16 & 14 & 2 & 8 & 2,29 \\
N/\% & 26,06 & 21,3 & 16,08 & 12,01 & 11,09 & 6,1 & 2,96 & 2,59 & 0,37 & 1,48 & \\
\hline Female & 91 & 67 & 56 & 45 & 48 & 28 & 14 & 12 & 1 & 8 & $2,41 *$ \\
N/\% & 24,59 & 18,1 & 15,13 & 12,16 & 12,97 & 7,57 & 3,78 & 3,24 & 0,27 & 2,16 & \\
\hline Male & 48 & 46 & 31 & 19 & 12 & 5 & 2 & 2 & 1 & 0 & 0 \\
N/\% & 28,91 & 27,7 & 18,67 & 11,44 & 7,23 & 3,01 & 1,2 & 1,2 & 0,6 & 0 & $\mathbf{1 , 6 4 *}$ \\
\hline Tutor & 78 & 59 & 52 & 35 & 35 & 17 & 8 & 6 & 2 & 4 & 2,14 \\
N/\% & 26,35 & 19,9 & 17,57 & 11,82 & 11,82 & 5,74 & 2,7 & 2,03 & 0,67 & 1,35 & \\
\hline Admin & 23 & 21 & 17 & 13 & 8 & 6 & 6 & 2 & 0 & 2 & 2,04 \\
N/\% & 23,47 & 21,4 & 17,34 & 13,26 & 8,16 & 6,12 & 6,12 & 2,04 & 0 & 2,28 \\
\hline Auxiliary & 29 & 24 & 14 & 14 & 15 & 8 & 2 & 4 & 0 & 2 & 1,78 \\
N/\% & 25,89 & 21,4 & 12,5 & 12,5 & 13,39 & 7,14 & 1,78 & 3,57 & 0 & 2,25 \\
\hline
\end{tabular}

*significant difference $(\mathrm{p}=0.000058)$

The most commonly reported MS complaints by location were those affecting the lower back, upper back and the neck area, followed by shoulders, knees and hands (fig. 1.). There were some minor variances present in the studied subgroups: a higher percentage of hand/arm symptoms was reported by auxiliary workers, as well as lower back complaints by administrative staff. The predominant type of MS complaint was ache/pain during movement (23.8\% of all reported symptoms), followed by discomfort (17.9\%) and stiffness $(17.2 \%)$ in the affected anatomical area. $10.35 \%$ of respondents indicated that the musculoskeletal symptoms interfered with their work on a daily basis and reduced their overall performance.

Fig. 1. Distribution of musculoskeletal complaints in the studied employees by location (in percentage).

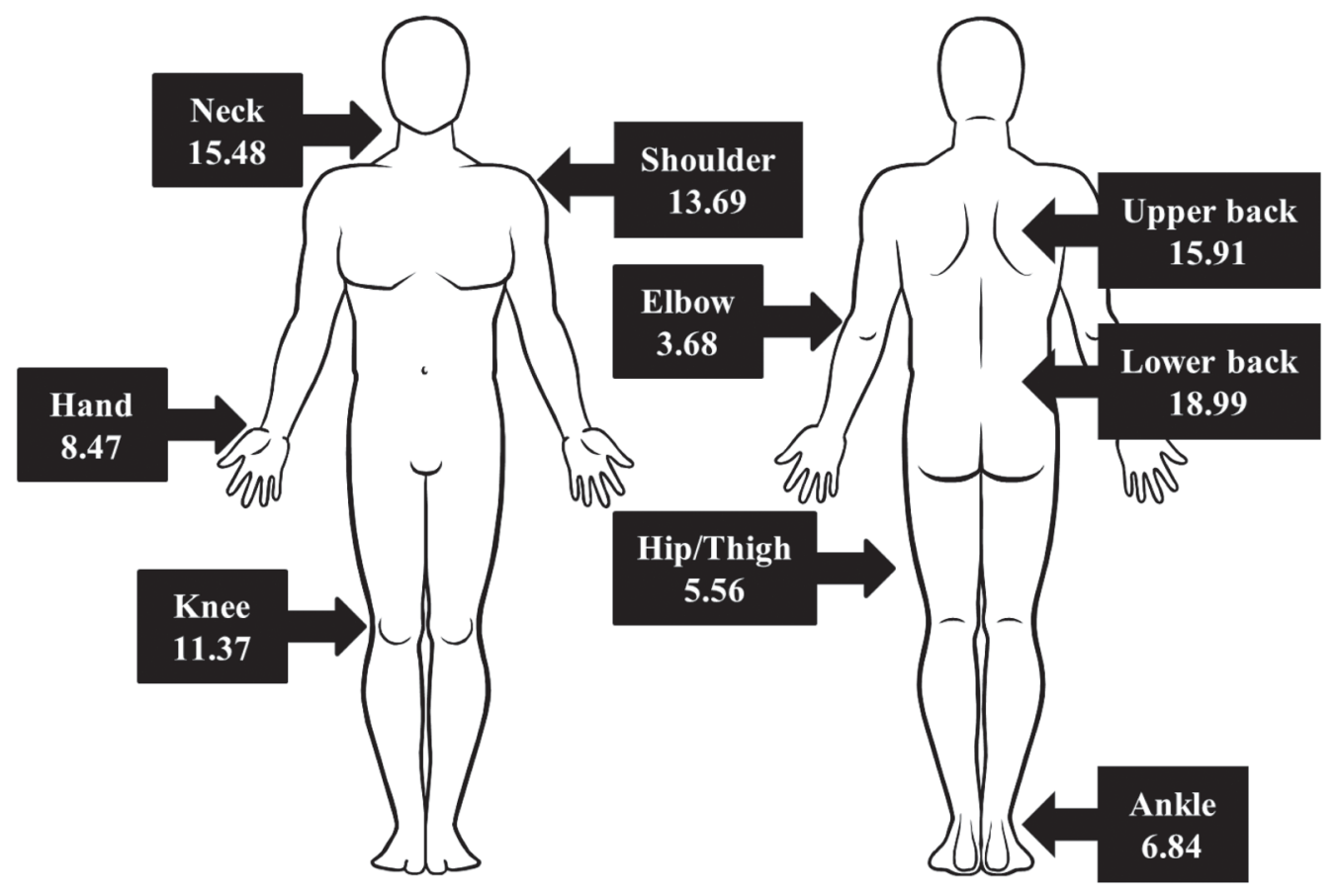

The correlation analysis found a single significant positive correlation - between the number of musculoskeletal complaints and the years of service $(r=0.11, \mathrm{p}=0.019)$, but none between the number of complaints and the workers' age.

The analysis of results from the Musculoskeletal Oc- cupational Risks Questionnaire showed that the most predominant hazard at the university was working with display screens (fig. 2.): $48.2 \%$ of male workers, $59.2 \%$ of females, $62.8 \%$ of tutors and $82.6 \%$ of the administrative staff reported working with display screens for at least half of the work day. 
Fig. 2. Distribution of musculoskeletal workplace hazards by duration of exposure for the studied population (in percentage).

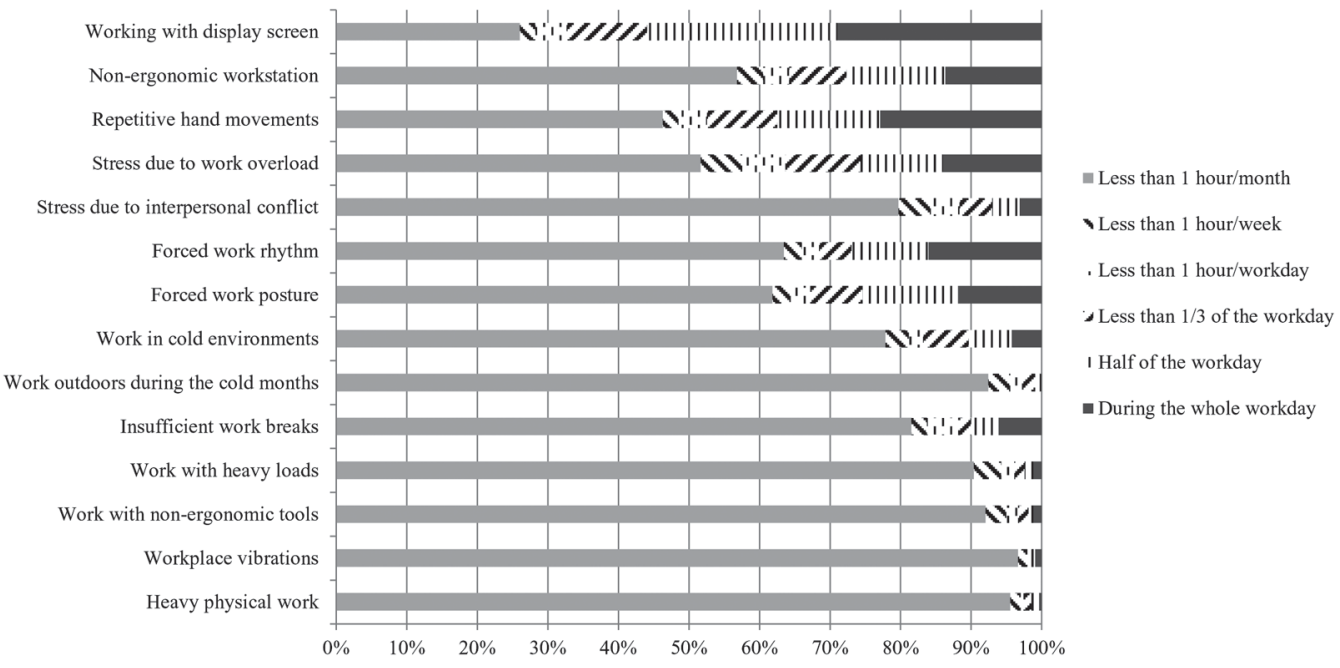

Other significant occupational risk factors were repetitive hand movements (the predominant issue for auxiliary workers, with $29.7 \%$ having to perform them for at least half the work day), working at a non-ergonomic work station, and work posture (prolonged sitting or standing). In comparison, only a minimal number of employees were exposed to hazards such as heavy physical work, workplace vibrations, carrying heavy loads or working outdoors in cold weather.

\section{DISCUSSION}

Period prevalence of MSDs is an important health indicator both in work-related and non-work related settings. In our study, the prevalence rate of university employees affected by MS complaints in the last 12 months was relatively high, but nevertheless concurrent with similar research on education workers, where the rate of MSDs ranges from $43 \%$ to $85 \%[4,9,10]$. This consistency in outcomes regarding MSDs in the education sector indicates that not only physically demanding jobs are at significant risk of MSDs.

Gender differences in the prevalence of MSDs are another specific focus of research, and, overall, the female gender is consistently shown to be at higher risk of MSDs than the male. The education sector seems to follow this trend. Similarly to our results, various studies indicate that female employees in the education sector, both in teaching and in administrative jobs, are more affected by MSDs than men [6,11-13].

The body parts most commonly associated with MSDs in the education sector are the back, neck and shoulders, outcomes that align with the findings in our study. De Ceballos \& Santos' results from a sample of 525 teachers found the most common musculoskeletal pains to be localized in the shoulders (31.6\%), upper back (27.8\%) and neck (27.2\%) [4]. Sirajudeen et al. found neck complaints $(53.5 \%)$ to be the most prevalent among college workers in Saudi Arabia, followed by lower back (43.3\%) and hand regions (31.6\%) [9]. Collins and O'Sullivan identified that the neck (58\%), shoulder $(57 \%)$ and lower back $(51 \%)$ showed the highest reported symptoms across a cohort of 852 office based university workers [11]. Mohan et al. observed that WRMSDs among academicians at a higher learning institute were predominantly neck pain (44.7\%), shoulder pain (40.4\%), upper and lower back pain $(33.3 \%)$ [14]. Similar results were obtained by Cheng et al., Algarni et al., Mohammadipour et al. $[5,10,15]$.

Working with video display screens turned out to be the most reported occupational hazard in our study for both administrative and teaching staff. Working with VDUs, paired with inappropriate work stations and prolonged sitting, is known to lead to complaints from the back, neck and shoulder regions, which were the most reported MSD locations in our study [3]. These issues predominantly affect female and more experienced workers. Ricco et al. found a clear association between the prevalence of MSDs in employees working with VDUs and the female gender, work experience and the weekly hours at work [12].

The observed significant positive correlation between the number of musculoskeletal complaints and the years of service, but not between the number of musculoskeletal complaints and the employees' age, indicates an occupational etiology of the reported MSDs, rather than an issue associated with older age of the workers. This result points towards possible prevention strategies against MSDs at the studied university setting - prevention needs to focus mainly on minimizing the exposure to occupational hazards, specifically non-ergonomic work arrangements, work movements and work postures. These can be further supplemented by measures to minimize the adverse effects of the MSD-associated occupational hazards: active work breaks, at-desk exercises, increased overall physical activity [16]. Of course, the afflicted employees should receive additional assistance in managing their MSDs, such as modified work stations, regular health checks and rehabilitation. A multifaceted and comprehensive approach to work-related musculoskeletal disorders in the workplace will lead to the best results in terms of reduced sick leave days, increased work ability and productivity, and happier workers [2]. 


\section{CONCLUSIONS}

Our results showed a high prevalence of MSDs among the studied groups, and the most reported locations of musculoskeletal complaints were in direct relation to the most reported ergonomic workplace hazards. Additionally, the positive correlation between the number of MS symptoms and the years of employment at the university strengthened the case for the occupational cause of the reported MSDs.

Prevention of WRMSDs in higher education should follow a comprehensive approach involving the identification, assessment and control of a number of ergonomic and organizational factors. Prevention activities also need to address sociodemographic factors such as gender, age and work experience. Similar studies in various occupational groups would further elucidate the etiological characteristics of these chronic, painful and often disabling diseases.

\author{
Abbreviations: \\ WRMSDs - work-related musculoskeletal disorders \\ MSDs - musculoskeletal disorders \\ MS - musculoskeletal \\ VDU - visual display unit
}

\section{Acknowledgements:}

This study was funded through Research Project 09/ 2018 by the Medical Faculty, Trakia University, Stara Zagora, Bulgaria, and is dedicated to the EU-OSHA 20202022 Healthy Workplaces Lighten the Load campaign.

\section{REFERENCES:}

1. EU-OSHA. Work-related musculoskeletal disorders - facts and figures. Luxembourg: Publications Office of the European Union. 19 February 2020. 80 p. [Crossref]

2. Widanarko B, Legg S, Devereux J, Stevenson M. The combined effect of physical, psychosocial/organizational and/or environmental risk factors on the presence of work-related musculoskeletal symptoms and its consequences. Appl Ergon. 2014 Nov;45(6):1610-1621. [PubMed]

3. da Costa BR, Vieira ER. Risk factors for work-related musculoskeletal disorders: a systematic review of recent longitudinal studies. Am J Ind Med. 2010 Mar;53(3): 285-323. [PubMed]

4. de Ceballos AG, Barreto Santos GB. Factors associated with musculoskeletal pain among teachers: sociodemographics aspects, general health and well-being at work. Rev Bras Epidemiol. 2015 JulSep;18(3):702-15. [PubMed]

5. Cheng HY, Wong MT, Yu YC, Ju YY. Work-related musculoskeletal disorders and ergonomic risk factors in special education teachers and teacher's aides. $B M C$ Public Health. 2016 Feb;16:137-145. [PubMed]

6.Morais BX, Dalmolin GL, Andolhe R, Dullius AI, Rocha LP. Musculoskeletal pain in undergraduate health students: preva- lence and associated factors. Rev ESC Enferm USP. 2019 Jul;53:e03444. [PubMed]

7. Penkala S, El-Debal H, Coxon K. Work-related musculoskeletal problems related to laboratory training in university medical science students: a cross sectional survey. BMC Public Health. 2018 Oct 29;18(1):1208. [PubMed]

8. Kuorinka I, Jonsson B, Kilbom A, Vinterberg $\mathrm{H}$, Biering-Sorensen $\mathrm{F}$, Andersson G, et al. Standardized Nordic questionnaires for the analysis of musculoskeletal symptoms. Appl Ergon. 1987 Sep;18(3):233-7. [PubMed]

9. Sirajudeen MS, Alaidarous M, Waly M, Alqahtani M. Work-related musculoskeletal disorders among faculty members of college of Applied Medical Sciences, Majmaah University, Saudi Arabia: a crosssectional study. Int J Health Sci (Qassim). 2018 Jul-Aug;12(4):18-25. [PubMed]

10. Algarni FS, Kachanathu SJ, AlAbdulwahab SS. A Cross-Sectional Study on the association of patterns and physical risk factors with musculoskeletal disorders among academicians in Saudi Arabia. Biomed Res Int. 2020 Aug;2020: 8930968. [PubMed]

11. Collins JD, O'Sullivan LW. Musculoskeletal disorder prevalence and psychosocial risk exposures by age and gen- der in a cohort of office based employees in two academic institutions. Int $J$ Ind Ergon. 2015 Mar;46:85-97. [Crossref]

12. Riccò M, Cattani S, Gualerzi G, Signorelli C. Work with visual display units and musculoskeletal disorders: a cross-sectional study. Med Pr. 2016 Dec;67(6):707719. [PubMed]

13. Özdinç S, Kayabýnar E, Özen T, Turan FN, Yýlmaz S. Musculoskeletal problems in academicians and related factors in Turkey. J Back Musculoskelet Rehabil. 2019; 32(6):833-839. [PubMed]

14. Mohan V, Justine M, Jagannathan M, Aminudin SB, Johari SH. Preliminary study of the patterns and physical risk factors of work-related musculoskeletal disorders among academicians in a higher learning institute. J Orthop Sci. 2015 Mar;20(2): 410-7. [PubMed]

15. Mohammadipour F, Pourranjbar M, Naderi S, Rafie F. Work-related musculoskeletal disorders in Iranian office workers: prevalence and risk factors. J Med Life. 2018 Oct-Dec;11(4):328-333. [PubMed]

16. Brakenridge CL, Chong YY, Winkler EA, Hadgraft NT, Fjeldsoe BS, Johnston V, et al. Evaluating short-term musculoskeletal pain changes in desk-based workers receiving a workplace sitting-reduction intervention. Int J Environ Res Public Health. 2018 Sep;15(9):1975. [PubMed]

Please cite this article as: Sandeva G, Tsvetkova V, Prakova G. Musculoskeletal Disorders and Associated Workplace Risk Factors in Higher Education Employees. J of IMAB. 2021 Oct-Dec;27(4):4108-4112.

DOI: https://doi.org/10.5272/jimab.2021274.4108

\author{
Address for correspondence: \\ Gergana Nikolaeva Sandeva \\ Department of Hygiene, Epidemiology, Infectious Diseases, Microbiology and \\ Parasitology, Medical Faculty, Trakia University, Stara Zagora, \\ 11, Armeyska Str, 6000 Stara Zagora, Bulgaria. \\ e-mail: geri_sandeva@yahoo.com,
}

